\title{
“NÃO QUEREMOS SER O FUTURO, SOMOS O PRESENTE": DES-OUTRIZAR \\ AS SUBJETIVIDADES POR UM PROCESSO FORMATIVO DECOLONIAL
}

\author{
Fábio Gonzaga Gesueli** \\ Tamires da Silva Oliveira ${ }^{* * *}$
}

\begin{abstract}
RESUMO
O objetivo de nosso artigo é desnaturalizar as construções epistemológicas e axiológicas do pensamento colonial produzido pelo ocidente, abrindo possibilidade para a construção de novas categorias de pensamento em relação ao processo de reconhecimento sobre nós mesmos e sobre os outros. Os conceitos de raça e racismo, vistos por uma perspectiva que denuncia o caráter estrutural dos dispositivos de colonialidade na construção da civilização ocidental, são historicizados por uma crítica que localiza as condições de possibilidade para o surgimento desse pensamento na filosofia liberal europeia, no século XVIII. Assim, queremos produzir uma discussão acerca dos dispositivos coloniais de poder e a violência operada por eles na construção das subjetividades, propagando discursos assimilacionistas e outrificadores em relação às diferenças culturais, naturalizando e imputando, via discursos racistas, determinadas características de cunho ontológico. Com isso, visamos enunciar que é possível a elaboração de uma prática
\end{abstract}

* DJONGA. Olho de tigre (Perfil \#22). Rio de Janeiro: Pineapple Stormtv: 2017. (3min 58s).

** ORCID iD http://orcid.org/0000-0003-1287-6811. Universidade Estadual de Campinas. Doutorando em História pela Universidade Estadual de Campinas. Mestre em Ciências da Religião e Licenciado em Ciências Sociais pela Pontifícia Universidade Católica de Campinas

*** ORCID iD https://orcid.org/0000-0001-8923-461X . Secretaria de Educação Municipal de Campinas. Professora da Rede Municipal de Campinas e Cientista Social.

Revista Páginas de Filosofia, v. 10, n. 1, p. 119-135, jan.-jun. 2021 
decolonial libertária, pautada na construção de categorias éticas e políticas permeadas pela luta antiracista.

Palavras-chave: colonialidade; racismo estrutural; subjetividades; des-outrificação.

\title{
“NÃO QUEREMOS SER O FUTURO, SOMOS O PRESENTE": DES-OUTRIZAR SUBJECTIVITIES THROUGH A DECOLONIAL FORMATIVE PROCESS ${ }^{1}$
}

\begin{abstract}
The aim of our article is to denaturalize the epistemological and axiological constructions of the colonial thought produced by the West, opening the possibility for the construction of new categories of thought in relation to the process of recognizing ourselves and others. The concepts of race and racism, seen from a perspective that denounces the structural character of the coloniality devices in the construction of Western civilization, are historicized by a critique that locates the conditions of possibility for the emergence of this thought in European liberal philosophy in the 18th century. Thus, we want to produce a discussion about the colonial power devices and the violence operated by them in the construction of subjectivities, propagating assimilationist and otherifying discourses in relation to cultural differences, naturalizing and imputing, via racist discourses, certain ontological characteristics. With this, we aim to enunciate that it is possible to elaborate a libertarian decolonial practice, based on the construction of ethical and political categories permeated by the anti-racist struggle.
\end{abstract}

Key-words: coloniality; structural racism; subjectivities; des-outrificação.

\section{INTRODUÇÃo}

A tarefa de dissolução de uma mórbida e virulenta mentalidade colonial mostra-se como uma tarefa marcada por um caráter de urgên-

\footnotetext{
1 O trecho da música "Olho de tigre" e o conceito de des-outrizar foram elaborados originalmente em português. A escolha de manter a poética do título e o conceito em sua língua de origem intenta confrontar a corrente epistemológica manifestadas nos enunciados, na língua e que aqui são problematizadas.
} 
cia em nossa contemporaneidade. Devido às contradições e processos marcados pelo racismo e pela colonialidade cada vez mais aparentes e desinibidos em nosso tempo, não podemos nos abster de uma reflexão inerentemente crítica acerca das formas de produção colonial das subjetividades, que propagam negações, destruição e esquecimento. A estrutura colonial opera em todos os âmbitos da sociedade - dado seu caráter estrutural - produzindo dispositivos de poder que, pautados por uma violenta epistemologia branca, ocidental, racista, misógina e heteronormativa, almejam destruir as subjetividades não brancas.

Nesse sentido, queremos dar voz aos contra-discursos engajados na luta antiracista que, ao se chocarem com a empresa colonial e seus dispositivos de poder, denunciam seu caráter narcísico, mostrando que a mentalidade colonial visa destruir tudo que não ela mesma. Assim, o exercício ético-político de construção de novas subjetividades a partir de uma interculturalidade e práticas libertárias são caminhos que possibilitam o estabelecimento de novas relações sociais, propiciando um mundo que não se estruture por categorias racistas de classificação e hierarquização das múltiplas formas de existências culturais e suas formas de ordenação do mundo.

\section{2. "SOBREVIVENDO NO INFERNO": ${ }^{2}$ RACISMO \\ ESTRUTURAL E COLONIALIDADE}

O pensamento eurocêntrico produzido no século XVII e XVIII, municiado pela expansão econômica capitalista e os processos de navegação que buscavam um suposto "descobrimento" de novos mundos, gera um tipo de arcabouço filosófico que irá pensar o homem branco europeu como ápice do processo civilizatório. Produz-se, assim, a construção de uma narrativa histórica teleológica que passa a subjugar outras formas de existência que não àquelas cosmopolitas. Dessa forma, desenvolve um ideário sobre o tipo de homem ideal, a saber, àquele do projeto iluminista.

Silvio de Almeida, em Racismo estrutural (2020), denuncia que o pensamento iluminista, com seus fundamentos filosóficos liberais operados em nome da razão, irá operar um projeto de universalização

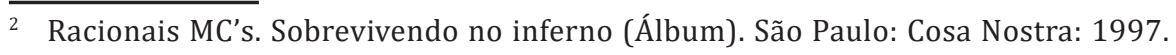

Revista Páginas de Filosofia, v. 10, n. 1, p. 119-135, jan.-jun. 2021 
da sociedade ocidental e seus processos econômicos e culturais. Em nome dessa razão universalista, o processo de expansão civilizatório desenvolve o colonialismo (ALMEIDA, 2020, p. 27). Esse projeto colonial, paradoxalmente às ideias liberais de igualdade, fraternidade e solidariedade, resultará em um processo vilanesco de morte e destruição de todos aqueles que não eram brancos. Assim, surgem os genocídios de milhares de povos originários, acompanhados de memoricídios, etnocídios e ecocídios. (SELIGMANN-SILVA, 2019).

Achille Mbembe também faz essa denúncia quando discorre acerca do projeto colonial e seus efeitos mortíferos, que ele denomina como necropolítica (2014a, 2014b, 2016). Para o autor camaronês, o processo de ocupação colonial desenvolvia-se pela "[...] apreensão, demarcação e afirmação do controle físico e geográfico [...]” (MBEMBE, 2016, p. 135). A máquina colonial e seus efeitos criam um ideário referente à "uma nova era da virilidade" constituindo um nacional-colonialismo que, operado por uma estrutura imperialista de expropriação e aniquilação, caracteriza a colônia como "[...] o lugar de exaltação da força onde se retempera a energia nacional” (MBEMBE, 2014a, p. 113).

Nesse sentido, o projeto iluminista que toma o homem como objeto passível de ser conhecido, passa a operar comparações e classificações que, ao serem pautadas na biologia, na economia, na psicologia e na linguística, irão criar uma "[...] distinção filosófico-antropológica entre civilizado e selvagem, que no século seguinte daria lugar o dístico civilizado e primitivo [...]" (ALMEIDA, 2020, p. 26, grifo no original). É nesse cenário histórico em que a raça e o racismo passam a desempenhar um papel fundamental para os processos de virulência do maquinário colonial. Em nome da escravidão perpetuada pela estrutura imperial colonialista e escravista, a classificação dos seres humanos a partir de suas características biológicas torna-se instrumento de determinismos biológicos e geográficos em relação às diferenças culturais. 0 discurso colonial passa a formular explicações de cunho moral em relação aos povos, designando que determinadas raças teriam diferenças em relação a outras. "Desse modo, a pele não branca e o clima tropical favoreceriam o surgimento de comportamentos imorais, lascivos e violentos, além de indicarem pouca inteligência." (ALMEIDA, 
2020, p. 29, grifo no original). Frantz Fanon em Em defesa da revolução africana (1980), também faz uma denúncia à essa hierarquização biológica e cultural desenvolvida nos processos de colonização. Nas palavras do autor:

Como as Escrituras se revelaram insuficientes, o racismo vulgar, primitivo, simplista, pretendia encontrar no biológico a base material da doutrina. Seria fastidioso lembrar os esforços empreendidos nessa altura: forma comparada do crânio, quantidade e configuração dos sulcos do encéfalo, características das camadas celulares do córtex, dimensões das vértebras, aspecto microscópico da epiderme, etc. 0 primitivismo intelectual e emocional aparecia como uma consequência banal, um reconhecimento de existência (FANON, 1980, p. 36).

A partir dessa classificação hierarquizante, o projeto colonial coloca-se como instrumento de cunho assistencialista, educacional e de manejo moral para o que ele definia como raças inferiores, fadadas a um suposto atraso cultural, ético, político e tecnológico. Ao definir raças pelo seu crivo liberal e iluminista, o colonialismo e sua mentalidade colonial queriam apresentar-se como "um benefício da civilização" (MBEMBE, 2014a, p. 117). Assim, podemos pensar que o projeto do colonialismo desenvolveu uma estrutura de pensamento colonial, um pensamento da colonialidade que desenvolveu uma colonização dos seres, dos saberes e dos poderes.

Como Anibal Quijano descreve:

A colonialidade é um dos elementos constitutivos e específicos do padrão mundial do poder capitalista. Sustenta-se na imposição de uma classificação racial/étnica da população do mundo como pedra angular do referido padrão de poder e opera em cada um dos planos, meios e dimensões, materiais e subjectivos, da existência social quotidiana e da escala societal (2009, p. 73)

Mas Quijano também faz uma distinção entre colonialismo e colonialidade. Essa classificação não desloca um conceito do outro, mas sim, demonstra como a estrutura política e econômica da máquina imperialista colonial, a saber, o colonialismo, desenvolveu simultanea- 
mente a si um ethos - se assim podemos denominar - de confirmação das estruturas violentas de classificação racista:

Colonialidade é um conceito diferente de, ainda que vinculado a colonialismo. Este último refere-se estritamente a uma estrutura de dominação/exploração onde o controle da autoridade política, dos recursos de produção e do trabalho de uma população determinada domina outra de diferente identidade e cujas sedes centrais estão, além disso, localizadas noutra jurisdição territorial. Mas nem sempre, nem necessariamente, implica relações racistas de poder. 0 colonialismo é, obviamente, mais antigo, enquanto a colonialidade tem vindo a provar, nos últimos 500 anos, ser mais profunda e duradora que o colonialismo. Mas foi, sem dúvida, engendrada dentro daquele e, mais ainda, sem ele não poderia ser imposta na intersubjectividade do mundo tão enraizado e prolongado (QUIJANO, 2009, p. 73).

Para Walter D. Mignolo, que fora impactado pelos trabalhos de Quijano, a colonialidade tomou tanto a natureza, quanto seus recursos naturais na cosmologia ocidental representada a partir de um sistema complexo, teológica e secularmente estruturado, para fabricação de uma epistemologia que legitimaria os usos da natureza em quantidades expressivas de produtos, mercantilizando o alimento e a vida $(2017$, p. 8).

Se retomarmos a análise de Almeida em relação ao racismo estrutural, após compreendermos que o projeto iluminista e liberal desenvolveu uma máquina imperial e colonialista, confirma-se a fala do autor de que, em nossa sociedade ocidental, nossos comportamentos e nossos processos institucionais operam a partir de uma mentalidade racista. 0 racismo, assim, "[...] é regra e não exceção" (ALMEIDA, 2019, p. 50). Nesse sentido, o racismo estrutural representa um coeficiente de normalidade perante as práticas subjetivas e institucionais da sociedade ocidental. Toda a estrutura desenvolvida pelo ideário iluminista, liberal e branco, subjuga àqueles que são considerados diferentes da salvaguarda teleológica do desenvolvimento histórico europeu. Vê-se assim que o racismo, articulado pela construção, classificação e hierarquização das raças, constitui-se como um processo histórico e político que, ao mesmo tempo, elabora uma normatização de subjetividades pautadas em uma estrutura de organização social inerentemente racista. 
Sueli Carneiro ratifica essa construção histórica do racismo, e evidencia que, se construído, ele é passível de ser destruído. Nas palavras da autora, "No entanto, a identidade étnica e racial é um fenômeno historicamente construído ou destruído". Dessa forma, não são as instituições e os indivíduos que criam ações racistas, mas antes, eles compactuam com esse ideário e o reproduzem, sendo operadores da violência arquitetada pelas categorias de pensamento coloniais (2011, p. 63).

\section{CONFABULANDO ESTEREÓTIPOS ${ }^{3}$ : OUTRIZAÇÃo E ASSIMILAÇÃo}

Como afirma Seligmann-Silva (2019), nos apresentando os conceitos de outrização e des-outrização a partir de Bonaventure Soh Bejeng Ndikung e seu texto Des-outrização como método (2019), a razão iluminista e seu projeto de esclarecimento tinham como fundamento um movimento de expansão "[...] para todos os cantos da Terra" (SELIGMANN-SILVA, 2019, p. 22). Assim, construiu-se um determinismo em relação às geografias e narrativas produzidas pelo pensamento colonial. Nesse sentido, o processo de outrizar é radicalmente distinto em relação àquilo que Ndikung nos convida a fazer, a saber, "mantenha o seu que eu mantenho o meu" ${ }^{4}$. A violência exercida pela razão eurocêntrica constrói classificações que desclassificam determinadas características, imputando-lhes o caráter de "outro". E como já dito, a máquina política e econômica do colonialismo, juntamente de sua racionalidade colonial, buscam destruir tudo aquilo que não seja condizente com si mesma. Dessa forma, o processo de outrificação diz respeito ao ato de aniquilar tudo aquilo que não é reconhecido como fruto da sociedade branca ocidental e seu ideário iluminista. Seligmann-Silva também ressalta que o modo de produção neoliberal exacerba esses processos, a partir da dinâmica capitalista que transforma todas as instâncias da vida em mercadoria. Nas palavras do autor:

3 Referência à música "Estereótipo" composta e interpretada pelo rapper Rashid, lançada em 2018.

4 Segundo Seligmann-Silva (2019, p. 21), “Bonaventure Soh Bejeng Ndikung propõe pensarmos um conceito de des-outrização como estratégia de crítica e desconstrução das geografias e narrativas que instituem poderes centrais em nossas sociedades. Seu texto para o catálogo da 21ํㅡㄹ Bienal de Arte Contemporânea Sesc_Videobrasil tem por título "Des-outrização como método" e leva como subtítulo uma frase em ngemba que, traduzindo, significa algo como "mantenha o seu que eu mantenho o meu".

Revista Páginas de Filosofia, v. 10, n. 1, p. 119-135, jan.-jun. 2021 
Se existe algo que não pode ser transformado imediatamente em lucro, como árvores e populações originárias, deve ser aniquilado. 0 outro é negado, e esse outro é tudo o que se opõe ao império do capital. A comodificação do mundo implica necessariamente sua própria morte. A geopolítica neoliberal recorta o mundo em função de sua exploração máxima. No campo político, Estados-nação articulam-se em blocos globalizados, desdobrando a lógica do extrativismo, manufatura e conversão em lucro. Esse modelo é uma continuidade do sistema colonial e reproduz as hierarquias que redundaram da colonialidade, tanto nas relações entre os blocos nacionais como em termos de uma nova racialização ontologizante (SELIGMANN-SILVA, 2019, p. 22)

Sueli Carneiro elucida alguns processos raciais que nos ajudam a compreender essa problemática da outrização. Para a autora, uma das principais características do racismo é aquela que diz respeito ao processo de aprisionamento dos racialmente não hegemônicos em subjetividades e imagens fixas e estereotipadas. A pluralidade das individualidades apenas é concedida aos brancos, enquanto para os negros, o movimento de constituição de diferenças é negado. A miscigenação, nesse sentido, é um discurso e um dispositivo de poder que busca o apagamento dos negros e o enbranquecimento de suas existências. Negros de pele clara, como ela intitula seu artigo. E assim nos diz, "A branquitude é, portanto, diversa e policromática. A negritude, no entanto, padece de toda sorte de indagações" (CARNEIRO, 2011, p. 71).

Ndikung explicita que o outro construído pela outrização propagada pela mentalidade colonial é substancial para o reconhecimento de indivíduos ou sociedades. Constitui-se um outro para definir aquilo que a suposta maioria hegemônica não deve ser, imputando-lhe por uma superfície de projeção racista, características estruturantes de suas subjetividades. É nesse sentido que o outro configura um receptáculo “[...] para todo tipo de características identitárias indesejáveis. Essa é a linha tênue que separa o mero desejo de "outrizar" para descobrir a própria identidade daquela outrização que discrimina e segrega" (NDIKUNG, 2019, p. 65).

Pensar a produção de subjetividades em sua estrutura dualística implica reconhecer o favorecimento de alguns sujeitos em detrimento do assujeitamento de minorias políticas. As formas de produção colonial 
hierarquizam, estratificam, classificam e invisibilizam a participação dos sujeitos subalternizados e silenciados frente ao conhecimento e reconhecimento de suas identidades quanto à raça, gênero ou classe. Essas subjetividades produzidas pela negação e pelo esquecimento tem seus aspectos identitários sequestrados por um processo doloroso e forçado à uma assimilação das identidades, dos saberes e das cosmologias eurocêntricas pelos subalternizados. Tal processo de assimilação se produz e reproduz em diferentes lócus de sociabilidade pelas relações de poder estabelecidas, onde determinados grupos e/ou instituições validam ou silenciam os saberes, fomentando ou subtraindo para fins de afirmar a soberania ocidental quanto aos modelos físicos, geográficos e subjetivos da existência.

Diferentemente do que se entendia enquanto projeto de colonização do paraíso tropical tupiniquim a partir de leituras com arquétipos de branquitude e negritude em certa (e considerável) medida romantizados, onde o processo de miscigenação brasileiro adquire conotação civilizatória pela assimilação e institucionalização dos valores ocidentalizantes; reitera-se com veemência a necessidade de se questionar o que Gilberto Freyre, em Casa-grande \& senzala (2003) coloca e enaltece como a ascendência familiar e patriarcal orientada pelo catolicismo português. Esse discurso expõe a centralidade do homem português e o quão necessário era para o desenvolvimento econômico e social da colônia assimilar o patriarcalismo branco e ocidental. Sobre esse processo de miscigenação racial e seu projeto para dar sustentáculos ao mito da "democracia racial", Carneiro afirma que não podemos nos esquecer de que esse argumento se constrói por uma trama histórica na qual é omitido "[...] o estupro colonial praticado pelo colonizador sobre mulheres negras e indígenas” (2011, p. 66). Compreendemos as especificidades da operação do colonialismo e da colonialidade quanto aos limites geográficos de seu processo expansionista, mas também consideramos as especificidades do que foi a prática colonialista desenvolvida pela máquina colonizadora escravista para os povos originários das américas e para os povos africanos.

Pelas vias de violência e sangue por onde esse processo trilhou seus caminhos, semeou-se a subalternização dos sujeitos que tiveram 
sua história e memória silenciados pelo suposto grito de progresso das subjetividades colonizadoras no desmantelamento das subjetividades invisibilizadas. Como afirma Carlos Alfredo Hosenbalg (1982) o problema da mobilidade social após a abolição da escravidão influenciou diretamente a distribuição geográfica de brancos e negros, além enfrentar as contrariedades expressas pelas práticas racistas da classe dominante. Contudo, também compreendemos que para além desse duplo distúrbio social, as práticas racistas enquanto ação das subjetividades brancas e patriarcais coagem e constrangem as subjetividades subalternizadas para a o que Hosenbalg (1957, p.71) entende como "[...] assimilação das minorias na sociedade mais ampla e o consequente desaparecimento de categorias étnicas e raciais enquanto tais." A negação da diferença que as subjetividades colonizadoras empreendem institui uma práxis de vigilância, classificação e violência que pressupõe o "universalismo, realização, eficiência instrumental e capacidade individual dentro de uma estrutura aberta de oportunidades". (HOSENBALG, 1957, p. 72).

Nesse sentido, Fanon em Pele negra, máscaras brancas (2008), constrói um pensamento que nos convida a pensar em uma abertura do mundo. Diferentemente do pensamento colonial, que faz o outro emergir como zona de decidibilidade de características lascivas e problemáticas, a partir da construção e classificação de raças como instituição da humanidade, o pensamento descolonial - e mais à frente o pensamento decolonial - traça um caminho radicalmente distinto. A dissolução das raças seria um movimento de libertação do homem dessas zonas de servidão e subjugamento e o caminho para construção de novas formas de humanidade. Na interpretação de Mbembe, assim ele nos diz:

Deve fazer-se surgir pelo processo através do qual o colonizado desperta para a consciência de si, apropriando-se subjectivamente do seu eu, desmonta a sua cerca e permite-se falar na primeira pessoa [...] Para Fanon, essa ascensão em humanidade só pode resultar de uma luta: a luta pela vida (MBEMBE, 2014b, p. 59) 


\section{4. "NÃO SABEM DA TUA LUTA, NÃO ENTENDEM SEU LINGUAJAR" 5: SUBJETIVIDADE, LIBERDADE E TRANSGRESSÃO}

Seja pela colonialidade do poder ou pela colonialidade dos saberes, precisamos, como tratam Manuel Tavares e Sandra Rosa Gomes, expandir os "horizontes epistemológicos e axiológicos" para considerar maneiras outras de formação de subjetividades que decorram da "diversidade e da diferença cultural" (2018. p.56). A produção de práticas outras, práticas que libertem as subjetividades pelo fortalecimento de outras dinâmicas de produção do saber e que insurge contra o que Maria Clara Araújo dos Passos aponta como o "fenômeno que desvaloriza, nega e oculta" as contribuições dos grupos historicamente dominados e subalternizados pela estrutura de violência racista e colonial (2019, p.1203).

Quanto à produção desse conhecimento universalizado e universalizante, Grada Kilomba (2019) nos convida a questionar: quem sabe ou não sabe e por que sabe ou não sabe? Essas questões desafiam a aparente universalização e neutralidade atribuídas aos saberes, à erudição e à ciência promovidas no espaço branco. Borrar a prática de objetificação das pessoas negras exige o reconhecimento da sistêmica subordinação desses sujeitos aos sujeitos brancos. 0 eurocentrismo, como aponta Kilomba, atribui credibilidade a determinadas ordens de conhecimento em detrimento de outras (apud Collins e Nkweto Simmonds, 2019, p. 53). Sejam os temas, paradigmas ou metodologias, todo o academicismo tradicional, a partir da reprodução das relações raciais, reflete os interesses políticos específicos da produção e reprodução de epistemologias validadas pela branquitude. Para a autora:

A epistemologia, derivada das palavras gregas episteme, que significa conhecimento, e logos que significa ciência, é a ciência da aquisição de conhecimento e determina que questões merecem ser colocadas (temas), como analisar e explicar um fenômeno (paradigmas) e como conduzir pesquisas para produzir conhecimento (métodos), e nesse sentido define não apenas o que é o conhecimento verdadeiro, mas também em quem acreditar e em quem confiar. Mas quem define quais perguntas merecem ser feitas? Quem as está perguntando? Quem as está explicando? E para quem as respostas são direcionadas? (KILOMBA, 2019, p. 54)

\footnotetext{
5 MC Tha. Valente. Sem gravadora: 2018. Plataformas digitais (3min 08s).
} 
Cabe-nos praticar aquilo que Rodrigo Corrêa Martins Machado e Ivanete Bernardino Soares compreendem como a destituição da "hierarquização dos saberes, de histórias, de línguas e de modos de ser" para experimentar o conhecimento que se produz alheio aos centros hegemônicos, superando o assujeitamento de negros, mulheres, indígenas e tantas outras minorias políticas, e assumir as desigualdades e injustiças sociais demarcados pelos desdobramentos da colonialidade (2021, p.11-12). A recíproca de um projeto formativo de subjetividades ansiado pela autora e educadora bell hooks ${ }^{6}$ exige uma práxis que exprima "diretamente a preocupação de questionar as parcialidades que reforçam os sistemas de dominação (como o racismo e o sexismo)" (2013, p.20). Defendemos, assim como hooks, o engajamento de quem fala e de quem escuta, ao valorizar o caráter testemunhal das falas dos sujeitos subalternizados enquanto "prática intelectual insurgente" (2013, p.23).

Ratificando a necessidade de impulsionar os sujeitos para uma práxis que produza subjetividades que confraternizem com as multiplicidades dos seres e saberes versada por Paulo Freire (1981), estabelecemos como ponto de indagação crítica a instituição desses saberes a partir da práxis formativa e da demarcação de uma epistemologia branca, ocidental, racista, misógina e heteronormativa na fundamentação da operação das instituições que participam na produção de subjetividades. Essa valorização se justifica por entendermos, assim como hooks, que o trabalho formativo, "proporciona espaço para as mudanças", onde "as alterações espontâneas que podem atuar como catalisadoras para evidenciar os aspectos únicos" concatenam as múltiplas subjetividades (2013, p. 21).

Experimentar o trabalho formativo pela decolonialidade das subjetividades, como argumenta a educadora Catherine Walsh, produz a translação mútua de conhecimentos, sem mesclá-las ou hibridizá-las (2019, p. 17). Concerne a essa produção de subjetividades a “[...]

6 Pseudônimo escolhido por Gloria Jean Watkins em homenagem à sua avó Bell Blair Hooks, escrito propositalmente em letras minúsculas com o intuito de dar visibilidade à sua produção e não à sua pessoa, rompendo, assim, com as convenções linguísticas e acadêmicas. 
construção de um novo espaço epistemológico [...]", que "inclua a recuperação e reconstrução da memória coletiva e do conhecimento coletivo" (WALSH, p. 19).

Na insurgência contra o que Carneiro aponta como "epistemicídio", viabilizado pelo banimento social e pela exclusão de oportunidades educacionais no processo formativo dos sujeitos subalternizados, faz-se imperativa a desnaturalização do rebaixamento da autoestima, e reconhecimento dos grupos invisibilizados enquanto "sujeitos de conhecimento" (2011, p. 93). A formação decolonial de subjetividades outras exige o "diálogo intercultural, de aprendizagem da liberdade e de uma cidadania emancipatória e democrática” (TAVARES \& GOMES, p.58). A retomada da interculturalidade, no entanto, exige engajamento à medida que uma formação intercultural não deve limitar-se à mistura, fusão ou assimilação das diferenças culturais. Walsh alerta:

[...] a lógica da interculturalidade compromete um conhecimento e pensamento que não se encontra isolado dos paradigmas ou das estruturas dominantes; por necessidade (e como um resultado do processo de colonialidade) essa lógica "conhece" esses paradigmas e estruturas. E é através desse conhecimento que se gera um "outro" conhecimento. Um pensamento "outro", que orienta o programa do movimento nas esferas política, social e cultural, enquanto opera afetando (e descolonizando), tanto as estruturas e os paradigmas dominantes quanto a padronização cultural que constrói o conhecimento "universal" do Ocidente (2019, p.15)

Para Sueli Carneiro, a inexistência de políticas que promovam a "igualdade de oportunidades" abstraem as subjetividades negras às estatísticas de desigualdade social (2001, p. 54). A urgência em desautorizar "ideias consagradas em nossa sociedade sobre a inexistência de um problema racial" se expressa em notória produção de estudos e debates acerca da determinação das condições necessárias "para a criação de um círculo virtuoso de mudança em contraposição ao círculo vicioso estabelecido pelas hierarquias de poder com base em raça, cor e aparência." (CARNEIRO, 2011, p.143). No entanto, a estruturação dos processos formativos que reforçam o ordenamento da supremacia branca a partir de ideologias de dominação e subordinação desenvolve 
sua narrativa ora pela invisibilização de subjetividades historicamente dominadas, ora pela "afirmação" que mantém a dinâmica de autorização e desautorização dos sujeitos subalternizados em sua integração a lógica universalista que rege as esferas políticas, sociais e culturais do aparato "patriarcal imperialista supremacista branco" empreendido pelo projeto colonizador (hooks, 2020, p. 54). A educadora ilustra tal arquétipo:

[...] Muitos de nós frequentaram universidades que não teriam aceitado nossa matrícula se não tivessem acontecido os movimentos por igualdade dirigidos a compensar os preconceitos de raça, sexo e classe social e o movimento para reconstrução (equivocadamente denominado de "ação afirmativa"). Era como se o uso da palavra "afirmativa" significasse que um grande "sim" estava sendo concedido aos desfavorecidos pelos favorecidos [...] (hooks, 2020, p. 54).

Hooks, então, pontua a necessidade de se reconhecer os movimentos de resistência à pressão dos valores de dominação das identidades subalternizadas enquanto um processo contínuo. A mentalidade colonizadora que "molda consciências e ações" apoiada, inclusive em "recompensas materiais" para submissão e assimilação dos sujeitos dominados, reclamam o engajamento para novos "modos de pensar e ser". 0 compartilhamento desse conhecimento produzido fora da lógica colonizadora fomentaria, portanto, a construção do que a educadora nomeia como "subculturas de autodeterminação no quadro da cultura do dominador." (2020, p. 57).

\section{CONSIDERAÇões FINAIS}

Os esforços para superar a lógica da colonialidade, como afirma Mignolo (2017), necessariamente questionam a modernidade; não como movimento de ascendência do pensamento, práticas e costumes no espaço-tempo, mas como invenção das sociedades ocidentais para um projeto colonizador sob mapeamento e exploração da conquista designada como "Novo Mundo". Com a colonização do tempo pela invenção renascentista da Idade Média e a colonização do espaço com a invasão da América pelas missões cristãs colonizadoras; a continuidade de um projeto que descolonize os saberes e as práticas é imprescindível 
na formação dos sujeitos; tanto para o posicionamento dos diferentes grupos, suas práticas e pensamentos, quanto contra a hierarquização da racionalidade moderna/colonial, racial, de gênero e de classe.

Sumariamente, compreender a estrutura colonial em todos os seus âmbitos, pela sua demarcação e afirmação no espaço e no tempo - que é físico e social - corrobora para compreensão do que foi e do que é o processo de assimilação das minorias nas sociedades globalizadas e globalizantes. Artifício este, também estruturado no processo de formação das subjetividades múltiplas, coagidas às formações universalizantes. A resistência, a revolta, a insurgência contra uma epistemologia branca, ocidental, racista, misógina e heteronormativa por parte de estudiosos e pensadores descoloniais não reside em elencar os problemas já conhecidos pelos pensadores, intelectuais e lideranças indígenas, por exemplo; mas na produção de pesquisas que des-outrizem e que questionem o próprio domínio hegemônico da academia.

Para Mignolo, o projeto descolonizador a ser empreendido reclama o foco na enunciação, de maneira a garantir o engajamento da desobediência epistêmica. Essa enunciação da epistemologia ocidental que posta a lógica da colonialidade acobertada pela retórica da modernidade precisa superar a estrutura de administração e controle manifestada a partir da transformação econômica e de pensamento ocorrida internamente na Europa, e entre Europa e suas colônias (2017, p. 6). Nesse sentido, é nossa tarefa questionar a política de cordialidade do colonizador para a efetiva inclusão, visibilização e participação dos sujeitos subalternizados na produção de um conhecimento que se estruture não pela lógica virulenta construída pelo universo colonial e seus racismos; mas sim, pela valoração das falas daquelas subjetividades, histórias e lutas dos sistematicamente oprimidos.

\section{REFERÊNCIAS}

ALMEIDA, Silvio Luiz de. Racismo Estrutural. São Paulo: Sueli Carneiro; Editora Jandaíra, 2020.

CARNEIRO, Sueli. Racismo, sexismo e desigualdade no Brasil. São Paulo: Selo Negro, 2011.

DOS PASSOS, Maria Clara Araújo. O currículo frente à insurgência decolonial: consti-

Revista Páginas de Filosofia, v. 10, n. 1, p. 119-135, jan.-jun. 2021 
tuindo outros lugares de fala. Cadernos de Gênero e Tecnologia (CGT). v. 12, n. 39, 2019. Disponível em: https://periodicos.utfpr.edu.br/cgt/article/view/9465. Acesso em 04 de julho de 2021.

FANON, Frantz. Em defesa da revolução africana. Lisboa: Livraria da Sá Costa Editora, 1980.

FANON, Frantz. Pele negra, máscaras brancas. Salvador: EDUFBA, 2008.

FREYRE, Gilberto. Casa-grande \& senzala: formação da família brasileira sob o regime da economia patriarcal. São Paulo: Global, 2003.

HASENBALG, Carlos. Raça, classe e mobilidade. In: GONZALEZ, Lélia; HASENBALG, Carlos. Lugar de negro. Rio de Janeiro. Editora Marco Zero. 1982. p. 67-102.

hooks, bell. Ensinando a transgredir: a educação como prática da liberdade. Tradução: Marcelo Brandão Cipolla. 2. Ed. São Paulo: Editora WMF Martins Fontes, 2017.

hooks, bell. Ensinando pensamento crítico: sabedoria prática. Tradução: Bhuvi Libanio. São Paulo: Elefante, 2020.

KILOMBA, Grada. Memórias da plantação: episódios de racismo cotidiano. Rio de Janeiro: Cobogó, 2019.

MACHADO, Rodrigo Corrêa Martins; SOARES, Ivanete Bernardino. Por um ensino decolonial de literatura. Revista Brasileira de Linguística Aplicada [online]. v. 00, n. 00, 2021. Disponível em: <https://doi.org/10.1590/1984-6398202116960>. Acesso em 4 de julho de 2021.

MBEMBE, Achille. Crítica da razão negra. Lisboa: Ántigona, 2014a.

MBEMBE, Achille. Necropolítica. In: Arte \& Ensaios, Rio de Janeiro, n. 32, p. 123, dez. 2016. e-ISSN. 2448-3.

MBEMBE, Achille. Sair da grande noite. Ensaio sobre a África descolonizada. Lisboa: Edições Pedago, 2014b.

MIGNOLO, Walter D. Colonialidade: o lado mais escuro da modernidade. Rev. bras. Ci. Soc. [online]. 2017, vol.32, n.94, e329402. Epub June 22, 2017. ISSN 1806-9053. http://dx.doi.org/10.17666/329402/2017

NDIKUNG, Bonaventure Soh Bejeng. Des-outrização como método (LEH ZO, A ME KE NDE ZA). In: 21ạ Bienal de Arte Contemporânea Sesc_Videobrasil: Comunidades imaginadas / Serviço Social do Comércio; Associação Cultural Vídeobrasil; direção artística de Solange 0. Farkas; curadoria de Gabriel Bogossian; Luisa Duarte; Miguel A. López, 2019, p. 63-67.

QUIJANO, Anibal. Colonialidade do poder e classificação social. In B. S. Santos, \& M. P. Meneses (Orgs.). Epistemologias do sul. Coimbra: Coimbra. 2009, p. 73-117.

Revista Páginas de Filosofia, v. 10, n. 1, p.119-135, jan.-jun. 2021 
SELIGMANN-SILVA, Márcio Orlando. DECOLONIAL, DES-OUTRIZAÇÃO: IMAGINANDO UMA POLÍTICA PÓS-NACIONAL E INSTITUIDORA DE NOVAS SUBJETIVIDADES. In: 21a Bienal de Arte Contemporânea Sesc_Videobrasil: Comunidades Imaginadas: Leituras / Serviço Social do Comércio; Associação Cultural Videobrasil, São Paulo: Sesc: Associação Cultural Videobrasil, 2019. 224 p.

TAVARES, Manuel; GOMES, Sandra Rosa. Multiculturalismo, interculturalismo e decolonialidade: prolegômenos a uma pedagogia decolonial. Dialogia. N. 29. Dossiê Temático: Educação e Multiculturalismo, maio/ago, 2018. Disponível em: <https://periodicos. uninove.br/dialogia/article/view/8646>. Acesso em 04 de julho de 2021.

WALSH, Catherine. Interculturalidade e decolonialidade do poder um pensamento e posicionamento "outro" a partir da diferença colonial. Revista Eletrônica da Faculdade de Direito da Universidade Federal de Pelotas (UFPel). V. 05, N. 1, Jan.-Jul., 2019. Disponível em: <https://periodicos.ufpel.edu.br/ojs2/index.php/revistadireito/ article/view/15002/10532>. Acesso em 07 de julho de 2021. 